\title{
Human Capital, Technology Adoption and Development*
}

\author{
A. Kerem Coşar ${ }^{\dagger}$ \\ The Pennsylvania State University.
}

January 26, 2009

\begin{abstract}
This paper presents a model of development in which skilled labor is an input in technology adoption. The model combines Nelson and Phelps (1966) type technology dynamics with a growth model in which intermediate goods are used to produce a final good. The intermediate good producers hire skilled labor to increase their productivity by adopting techniques from an exogenously evolving stock of world knowledge. I solve for the stationary equilibrium and derive analytic expressions for steady state income level and wage premium. In a quantitative exercise, I calibrate the model and compare its predictions with data. The model successfully accounts for cross-country income differences and within-country wage premia on skilled labor. These results strengthen the idea that different types of human capital perform separate tasks and should not be aggregated into a single stock of human capital in development accounting exercises. The availability of skilled labor is potentially much more important for development than such aggregative exercises have so far suggested.
\end{abstract}

JEL Classification: O33, O41

Keywords: Total Factor Productivity, Human Capital, Technology Adoption.

*I am grateful to Andrés Rodríguez-Clare for his continuous support and guidance. I also would like to thank to Ed Green, Nezih Guner, Alexander Monge-Naranjo, Barry Ickes, Stephen Parente, Neil Wallace and Ruilin Zhou whose comments and suggestions contributed substantially to this paper. All remaining errors are mine.

$\dagger^{\dagger}$ Department of Economics, The Pennsylvania State University, University Park, PA 16802. E-mail: cosar@psu.edu. 


\section{Introduction}

As it is well-known in growth literature, productivity differences explain a significant part of the variation observed in cross-country income distribution. ${ }^{1} \mathrm{~A}$ major determinant of productivity is the set of technologies available to firms in a country. The model presented here demonstrates that productivity differences may arise as a result of differences in skilled labor endowments which facilitate the adoption of technologies from an exogenously available set.

The idea that a link exists between technology adoption and human capital is not new. The line of thought initiated by Nelson and Phelps (1966) suggests that the role of human capital in development may go beyond its role as a mere factor of production. In this approach, human capital, in general, and education, in particular, help people to perceive, evaluate and implement new production techniques and inputs.

Empirical literature supports this approach. Using aggregate data, Benhabib and Spiegel (1997, 2005) as well as Papageorgiou (2003) find that specifying human capital as a determinant of productivity level, instead of using it as an input in the production function, gives better results in growth regressions. On a micro-level, Doms et.al. (1997) show that plants with a higher share of workers in skilled occupational categories or with higher educational levels use a greater number of advanced technologies. Foster and Rosenzweig (1995) document that in the wake of the "Green Revolution" period in India, the profitability of adopting new high-yield seed varieties and chemical fertilizers is increasing in the education level of farmers.

Human capital may affect technological diffusion through various channels. ${ }^{2}$ One channel is international trade which makes the transfer of embodied technology possible. Caselli and Coleman (2001), and Caselli and Wilson (2004) demonstrate that the amount of embodied technology in imported capital goods is positively related to the level of educational attainment. Another avenue is foreign direct investment. $\mathrm{Xu}(2000)$ demonstrates that the level of human capital is a key factor in explaining the level of technology diffusion from multinational companies to their host countries. Trade in ideas, as reflected by international patenting and licensing, constitutes yet another channel through

\footnotetext{
${ }^{1}$ Notable papers documenting the sources of income differences are Klenow and RodríguezClare (1997), Hall and Jones (1997) and Caselli (2005).

${ }^{2}$ For a survey of international technology diffusion, see Keller (2004).
} 
which technology flows across borders. Using patenting data of OECD countries, Eaton and Kortum (1999) estimate a model of bilateral diffusion of knowledge. According to their findings, human capital of the receiving country, measured as average years of schooling, has a significant positive impact on patenting after controlling for the degree of intellectual property protection, cost of patenting and research intensity.

The theoretical contribution of the paper is to embed the Nelson and Phelps (1966) idea into a general equilibrium model. A homogenous final good is produced competitively by combining unskilled labor with intermediate goods. The producers of intermediate varieties operate with a constant returns to scale technology employing capital only. The productivity of an intermediate variety is a product characteristic that affects its contribution to the production of the final good. A technology adoption function describes how skilled labor helps firms to augment their productivity levels by adopting techniques from an exogenously growing world knowledge stock. The demand for a variety is increasing in its productivity in the final good production. Hence, intermediate good producers have an incentive to hire skilled labor by paying them out of the positive operating profits. Skilled labor share of the workforce is the key exogenous variable in my model.

I show the existence of a stationary equilibrium and derive analytical expressions for the steady state income level and wage premium. I calibrate the model and undertake a quantitative exercise to evaluate its success in explaining crossand within-country income differences. The key parameter of the technology adoption function, the curvature of skilled labor, is calibrated to the US wage premium. Using these parameters, I predict income levels and wage premia for a group of countries.

As a theory of development, the model does a good job in replicating patterns of cross-country income levels by generating large productivity differences. The model simultaneously generates within-country income differences in the form of a wage premium for skilled labor. For a subset of countries with available data, the model performs reasonably well in fitting the wage premia data as well. The main quantitative contribution of the paper is the ability to simultaneously account for cross- and within country income differences.

This paper does not address the endogenous formation of skills. The question I am trying to answer is simply how far we can go in explaining income 
dispersion through observed skilled labor endowments. Recent models of endogenous skill formation include Manuelli and Seshadri (2005) and Erosa et. al. (2007)

Relation to the Literature This paper contributes to the literature that seeks to explain how countries benefit from an ever expanding technology frontier. Griffith et.al. (2004), Howitt (2000), Klenow and Rodríguez-Clare (2005), and Parente and Prescott (1994), among others, are contributions in this line. All these papers emphasize the role of physical investment and formal research and development (R\&D) expenditures in augmenting firm-level productivity. The model presented here takes a different approach. It argues that whereas many R\&D activities are geared towards product innovation, certain process innovations on the factory floor or the introduction of new inputs to the production process do not necessarily involve formal R\&D activities. To quote R.J. Gordon who is reporting on anectodal evidence from his visits to six US plants in various industries,

Clearly, much of the effort directed at productivity improvement we witnessed was not being achieved within any kind of formal R\&D activity, but could be classified under the general rubric of "incremental tinkering". - Gordon (2000).

It is conceivable that the knowledge needed to undertake such "incremental tinkering" on the factory floor is based on basic engineering and operations research principles. As a result, $R \& D$ intensity data misses a wide range of technology adoption efforts undertaken at firm level. This mismeasurement especially applies to developing countries which, according to UNESCO (1975), only perform $16 \%$ of global R\&D expenditures in 1996. Firms in developing countries have means other than formal $R \& D$ to benefit from the evolution of the frontier. Hence, I argue that many "incremental tinkering" activities are missed by the existing R\&D measures.

This last point is also made by Klenow and Rodríguez-Clare (2005) who build a model of technology diffusion where $R \& D$ is needed to adopt technologies. Using data on R\&D investment rates, their model delivers the results that poor countries have R\&D investment rates that are too low to explain their income levels. They conclude that the true research intensities must be higher than 
the measured ones and call for further research to measure "research". The quantitative application of my model contributes to the literature by proposing an alternative measure of a country's true research effort through its entire stock of skilled labor defined as scientists and engineers.

Another contribution of the paper is to explain cross-country income differences consistently with returns to skills within countries. Growth-accounting exercises based on the Nelson and Phelphs framework, such as Benhabib and Spiegel (1997, 2005) and Papageorgiou (2003), can not take stock of the skill premium implications of particular functional forms. I construct a general equilibrium model and I am thus able to discipline the adoption technology by the evidence on wage premium.

The remainder of the paper is structured as follows: Section two introduces the economic environment, describes the equilibrium concept, and presents analytic steady state solutions. Section three presents the quantitative exercise, pins down parameter values through calibration and compares model predictions with data. Section four concludes.

\section{Model Economy}

At time $t$, the economy is composed of a continuum of identical households of measure one, intermediate goods producers with a mass of $M_{t}$, a representative firm producing a final good and a government.

Each household consists of workers with measure $L_{t}$. Population grows by the rate $g_{\ell}$,

$$
\dot{L}_{t}=g_{\ell} L_{t}
$$

There are two types of workers in the economy: skilled and unskilled. A fraction $s \in(0,1)$ of each household is skilled and the rest is unskilled. Each unskilled worker is endowed with $u$ units of efficiency labor and one unit of time. Aggregate endowment of skilled and unskilled labor are $s L_{t}$ and $u(1-s) L_{t}$ respectively.

Besides the labor market, there are capital and financial markets in operation where intermediate good producers rent capital from households, and households can trade one-period bonds and the shares of these firms among each other. Now I turn to the description of production technologies. 


\section{$2.1 \quad$ Production}

The structure of production is similar to Howitt (2000). There is a final good and a continuum of intermediate goods indexed by $i$. The final good can be consumed or employed as capital in the production of intermediate goods. It is produced competitively by a representative firm using intermediate goods and unskilled labor:

$$
Y_{t}=L_{u, t}^{1-\alpha}\left[M_{t}^{-(1-\alpha)} \int_{0}^{M_{t}} A_{t}(i) \frac{x_{t}(i)^{\alpha}}{\alpha(1-\alpha)} d i\right]
$$

where $x_{t}(i)$ is the quantity of intermediate good used and $A_{t}(i)$ is its productivity. The normalization with respect to $M_{t}$ eliminates the growth effect of expanding intermediate good varieties. ${ }^{3}$ The final good producer takes the unskilled wage $w_{u, t}$ and intermediate good prices $p_{t}(i)$ and productivity levels $A_{t}(i)$ as given, and solves the static problem of maximizing (2.1) by optimally choosing $L_{u, t}$ and $x_{t}(i)$ every period.

The marginal product of each variety is independent of other varieties used in production. Each variety $i$ is a distinct product and its producer has a monopoly right over its supply. ${ }^{4}$ The marginal product of each variety goes to infinity as its quantity goes to zero. This implies that, for any price level, the representative final good firm demands a positive amount of each available variety.

The number of varieties grows proportionally to the size of the population,

$$
\dot{M}_{t}=\varphi L_{t}
$$

This assumption eliminates scale effects. The ratio of the population to varieties

\footnotetext{
${ }^{3}$ This channel is well understood through the contribution of endogenous growth models in the style of Romer (1990). In the context of technology diffusion, Barro and Sala-i Martin () study the effects of increasing product varieties through imitation by the South. I abstract from this source of growth since my focus here is on the evolution of what one can call process efficiency, and not TFP gains through expanding product variety.

${ }^{4}$ This assumption is not crucial for the argument here. One can write a CES composite of differentiated intermediate goods, such as$$
Y_{t}=L_{u, t}^{1-\alpha}\left[M_{t}^{-(1-\gamma)} \int_{0}^{M_{t}} A_{t}(i) \frac{x_{t}(i)^{\gamma}}{\gamma(1-\gamma)} d i\right]^{\frac{\alpha}{\gamma}}
$$

and derive the same results. The analysis here corresponds to the case $\gamma=\alpha$.
} 
monotonically converges to the constant given by:

$$
\lim _{t \rightarrow \infty} \frac{L_{t}}{M_{t}}=\frac{g_{\ell}}{\varphi}
$$

which I assume is equal to one by setting $\varphi=g_{\ell} .{ }^{5}$ The number of unskilled production workers per variety converges to a constant as well:

$$
\ell_{u}=\frac{L_{u, t}}{M_{t}}=\frac{L_{u, t}}{L_{t}} \frac{L_{t}}{M_{t}}=u(1-s)
$$

The last equality holds in equilibrium where unskilled labor demand $L_{u, t}$ is equal to its supply $u(1-s) L_{t}$. I also assume that the two types of labor cannot be substituted with each other.

Using these results in (2.1), I can restate the production function of the representative final good producer as

$$
Y_{t}=\int_{0}^{M_{t}} A_{t}(i) \frac{x_{t}(i)^{\alpha} \ell_{u}^{1-\alpha}}{\alpha(1-\alpha)} d i .
$$

The demand for an intermediate good is given by the inverse demand function: ${ }^{6}$

$$
p_{t}(i)=\frac{A_{t}(i)}{1-\alpha} x_{t}(i)^{\alpha-1} \ell_{u}^{1-\alpha}
$$

which yields total revenues as

$$
\text { Revenue }\left[x_{t}(i)\right]=\frac{A_{t}(i)}{1-\alpha} x_{t}(i)^{\alpha} \ell_{u}^{1-\alpha}
$$

Now I introduce the technology for producing intermediate goods. Capital is the only input and the production function is given by:

$$
x_{t}(i)=\frac{k_{t}(i)}{A_{t}(i)}
$$

\footnotetext{
${ }^{5}$ This assumption is not innocuous when one compares income levels across countries unless one also assumes identical population growth rates. This is what I implicitly do in the quantitative section.

${ }^{6}$ This is derived by the solution to the problem$$
\max _{\left\{x_{t}(i)\right\}, \ell_{u, t}} \int_{0}^{M_{t}} A_{t}(i) \frac{x_{t}(i)^{\alpha} \ell_{u}^{1-\alpha}}{\alpha(1-\alpha)} d i-\int_{0}^{M_{t}} p_{t}(i) x_{t}(i) d i-\ell_{u, t} M_{t} w_{u, t} .
$$ 
which has the feature that more productive varieties also require a more capital intensive production technology. Intermediate goods producers rent capital at a cost of $R_{t}$. The associated cost function is given by:

$$
\operatorname{Cost}\left[x_{t}(i)\right]=R_{t} A_{t}(i) x_{t}(i)
$$

The demand for capital is determined by setting marginal cost equal to marginal revenue which yields

$$
R_{t}=\frac{\alpha}{1-\alpha}\left(\frac{x_{t}(i)}{\ell_{u}}\right)^{\alpha-1} .
$$

Note that nothing in (2.5) depends on firm characteristics. All firms supply the same quantity of intermediate good, i.e.,

$$
x_{t}(i)=x_{t}
$$

Static operating profits after rental payment is given by:

$$
\pi_{t}(i)=A_{t}(i) x_{t}^{\alpha} \ell_{u}^{1-\alpha}
$$

Since the profit for a variety is increasing in its efficiency in the production of the final good, intermediate good producers have an incentive to invest in the augmentation of $A_{t}(i)$. In the following subsection, I describe the evolution of the productivity term $A_{t}(i)$ as a function of skilled labor employed in the process.

\subsection{Technology Dynamics}

The evolution of the technology motivated by the technology adoption model of Nelson and Phelps (1966). At each period, there is a world stock of ideas of size $T_{t} \cdot{ }^{7}$ This stock exogenously grows at a constant rate $\lambda>0$,

$$
\dot{T}_{t}=\lambda T_{t}
$$

For each firm, however, the growth rate of $A_{t}(i)$ depends on the number of skilled labor employed and the current distance to $T_{t}$. When the firm hires

\footnotetext{
${ }^{7}$ Nelson and Phelps refer to $T_{t}$ as 'theoretical level of technology' and to $A_{t}$ as 'technology in practice'.
} 
$\ell_{s, t}(i)$ measure of skilled labor, its technology evolves according to

$$
\dot{A}_{t}(i)=\ell_{s, t}^{\beta}(i)\left(\frac{T_{t}}{A_{t}(i)}\right)^{\eta} A_{t}(i) .
$$

The functional form reflects the two mechanisms affecting the evolution of productivity. The first mechanism is automatic diffusion from the frontier given by the term $T / A$. The bigger the gap to the frontier, the higher is the speed of the productivity increase. The second mechanism is the employment of skilled labor by a firm. The following restrictions on the two technology adoption parameters $(\beta, \eta)$ guarantee that the firm problem of optimal skilled labor choice has a solution:

$$
\beta \in(0,1)
$$

and

$$
\eta \in[\beta, 1]
$$

For the rest of the analysis, I restrict attention to the symmetric case where a representative firm with average productivity $A_{t}$ is given by:

$$
A_{t}=\frac{1}{M_{t}} \int_{0}^{M_{t}} A_{t}(i) d i
$$

By symmetry, the representative firm employs skilled labor of measure

$$
\ell_{s, t}=\frac{s L_{t}}{M_{t}}=s
$$

Using (2.2) and (2.11) in (2.8), the law of motion for technology is given by the function

$$
\dot{A}_{t}=s^{\beta}\left(\frac{T_{t}}{A_{t}}\right)^{\eta} A_{t},
$$

which has the limit property

$$
\lim _{t \rightarrow \infty} \frac{A_{t}}{T_{t}}=\left(\frac{s^{\beta}}{\lambda}\right)^{\frac{1}{\eta}} .
$$

The share of skilled labor in employment, $s$, has a level effect on the distance to the frontier and on output.

Having introduced the static profit maximization and the adoption technol- 
ogy, we can now define the firms' dynamic problem. The discount rate used by the firm is equal to the interest rate $r_{t}$ in the bond market. Let $w_{s, t}$ be the wage rate for skilled labor. Firms rent capital and hire skilled labor by rationally anticipating the future path $\left\{R_{t}, w_{s, t}, r_{t}\right\}_{t=0}^{\infty}$ of factor prices and the interest rate. Since they face a downward-sloping demand curve, they earn strictly positive rents given by $\pi_{t}=A_{t} x_{t}^{\alpha} \ell_{u}^{1-\alpha}$. Skilled labor is paid out of this rent and the expenditure $w_{s, t} \ell_{s, t}$ can be considered as a technology adoption investment. The net profit after all factor payments is distributed as dividends and is given by:

$$
\Pi_{t}=A_{t} x_{t}^{\alpha} \ell_{u}^{1-\alpha}-w_{s, t} \ell_{s, t}
$$

Starting with an initial technology level $A_{0}$, representative firm's problem is to choose factor demands $\left\{k_{t}, \ell_{s, t}\right\}_{t=0}^{\infty}$ in order to maximize the discounted sum of dividends,

$$
V\left(A_{0}\right)=\max \int_{t=0}^{\infty} e^{-\bar{r}(t) \cdot t} \Pi_{t} d t
$$

subject $(2.4),(2.7),(2.8),(2.12)$ and the average interest rate between times

0 and $t$ is defined as $\bar{r}(t)=(1 / t) \cdot \int_{0}^{t} r_{v} d v$. As discussed in the Appendix, dividends are positive in steady state.

Total dividends, $D_{t}=M_{t} \Pi_{t}$, are collected by the households who own the firms. Next, I turn to the description of the household problem.

\subsection{Households}

The representative household is composed of two types of members: skilled and unskilled. I assume that the fraction of skilled members, $s$, is exogenously given. The representative household is endowed with $(1-s) u L_{t}$ units of efficiency units of unskilled labor and $s L_{t}$ units of skilled labor. Both types of labor are supplied inelastically.

The representative household owns physical capital $K_{t}$ which depreciates by a rate of $\delta$. It accumulates capital by investing $(1+\theta) \mathrm{N}_{\mathrm{t}}$ out of its budget. The term $\theta$ is the time-invariant tax/subsidy rate that the government implements on purchases of investment goods. Households' capital stock evolves according to

$$
\dot{K}_{t}=\mathrm{N}_{\mathrm{t}}-\delta K_{t}
$$

Households are also endowed with equal shares of the representative inter- 
mediate good producer denoted by $a_{t}$. These shares can be traded any period at post-dividend share prices given by $q_{t}$. There is a market for bonds with one period maturity where households can borrow and lend by the market interest rate $r_{t}$. Bond holdings are given by $b_{t}$.

Let $C_{t}$ denote the total consumption of the household. The budget constraint is given by

$C_{t}+(1+\theta) \mathrm{N}_{\mathrm{t}}+q_{t} \cdot S_{t}+B_{t}=w_{s, t} s L_{t}+w_{u, t}(1-s) u L_{t}+R_{t} \cdot K_{t}+D_{t} \cdot a_{t}+\left(1+r_{t}\right) b_{t}+Z_{t}$,

where $S_{t}$ is purchase of new shares, $B_{t}$ is purchase of new bonds, $Z_{t}$ is tax rebates (or lump-sum taxation) and $a_{t}$ is fraction of intermediate firm equity owned by the household. The law of motion for $a_{t}$ and $b_{t}$ are given by

$$
\dot{a}_{t}=S_{t}
$$

and

$$
\dot{b_{t}}=B_{t}
$$

Household members only value consumption. Members equally split the total consumption $C_{t}$. Momentary utility of a member is given by

$$
u\left(C_{t} / L_{t}\right)=\ln \left(C_{t} / L_{t}\right)
$$

The future path of dividends and tax rebates, $\left\{D_{t}, Z_{t}\right\}_{t=0}^{\infty}$, as well as that of prices, $\left\{q_{t}, R_{t}, w_{u, t}, w_{s, t}\right\}_{t=0}^{\infty}$, are taken as given by the household. The problem faced by the representative household with initial endowments $\left(a_{0}, b_{0}, K_{0}\right)$ is then to make consumption and investment decisions $\left\{C_{t}, \mathrm{~N}_{\mathrm{t}}\right\}_{t=0}^{\infty}$, and asset trades $\left\{S_{t}, B_{t}\right\}_{t=0}^{\infty}$ to maximize the discounted sum of utility,

$$
\begin{aligned}
U\left(a_{0}, b_{0}, K_{0}\right) & =\max \int_{0}^{\infty} e^{-\rho \cdot t} L_{t} u\left(C_{t} / L_{t}\right) d t \\
& =\max \int_{0}^{\infty} e^{-\left(\rho-g_{\ell}\right) t} \ln \left(C_{t} / L_{t}\right) d t
\end{aligned}
$$

subject to the constraints $(2.15),(2.16),(2.17)$ and (2.18) under the assumption $\rho>g_{\ell}$.

Finally, the government implements the tax-subsidy policy $\left(\theta,\left\{Z_{t}\right\}\right)$ with a 
balanced budget:

$$
\theta \mathrm{N}_{\mathrm{t}}=Z_{t}
$$

\subsection{Equilibrium}

An equilibrium for this economy is a tax rate $\theta$ and sequence of government rebates $\left\{Z_{t}\right\}_{t=0}^{\infty}$, a set of prices $\left\{p_{t}, w_{s, t}, w_{u, t}, R_{t}, r_{t}, q_{t}\right\}_{t=0}^{\infty}$, a final good producer with factor demands $\left\{L_{u, t}, x_{t}\right\}_{t=0}^{\infty}$, intermediate good producers of measure $M_{t}$ with factor demands $\left\{k_{t}, \ell_{s, t}\right\}_{t=0}^{\infty}$, identical households of measure one who own capital stock $\left\{K_{t}\right\}_{t=0}^{\infty}$, labor endowments $\left\{s L_{t},(1-s) u L_{t}\right\}_{t=0}^{\infty}$ and undertake sequences of asset trades $\left\{S_{t}, B_{t}\right\}_{t=0}^{\infty}$, consumption and investment decisions $\left\{C_{t}, \mathrm{~N}_{\mathrm{t}}\right\}_{t=0}^{\infty}$, such that

1. given $\left\{w_{u, t}, p_{t}\right\}_{t=0}^{\infty}$, the representative final good producer demands the input bundle $\left\{L_{u, t}, x_{t}\right\}_{t=0}^{\infty}$ that minimizes its costs,

2. given $\left\{w_{s, t}, R_{t}, r_{t}\right\}_{t=0}^{\infty}$, factor demands $\left\{k_{t}, \ell_{s, t}\right\}_{t=0}^{\infty}$ solve the representative intermediate good producer's problem,

3. given $\left\{D_{t}, Z_{t}, q_{t}, R_{t}, r_{t}, w_{u, t}, w_{s, t}\right\}_{t=0}^{\infty}$, consumption, investment, and asset trade decisions $\left\{C_{t}, \mathrm{~N}_{\mathrm{t}}, S_{t}, B_{t}\right\}_{t=0}^{\infty}$ solve the representative household problem, yielding a capital supply of $\left\{K_{t}\right\}_{t=0}^{\infty}$,

4. capital market clears: for all $t, k_{t} M_{t}=K_{t}$,

5. labor markets clear: for all $t, \ell_{s, t} M_{t}=s L_{t}$ and $\ell_{u, t} M_{t}=(1-s) u L_{t}$,

6. asset and bond markets clear with no trade since all households are identical: for all $t$ we have $S(t)=0$ and $B(t)=0$,

7. the intermediate goods market clears: the demand for $x_{t}$ by the final good producers is met by its supply,

8. the final good market clears: for all $t$, we have $Y_{t}=C_{t}+\mathrm{N}_{\mathrm{t}}$,

9. government's budget is balanced: for all $t$, we have $\theta \mathrm{N}_{\mathrm{t}}=Z_{t}$. 


\subsection{Aggregation and the Steady State}

I first aggregate the variables of interest generated by the model and then analyze their steady state properties. The existence of a steady state equilibrium is shown at the Appendix.

I have shown that all intermediate good producers supply an equal amount of $x_{t}$. The final good producer employs $\ell_{u}$ unskilled workers per intermediate good. Aggregating (2.3) over $i$, aggregate output is equal to:

$$
Y_{t}=\frac{x_{t}^{\alpha} \ell_{u}^{1-\alpha}}{\alpha(1-\alpha)} \int_{0}^{M_{t}} A_{t}(i) d i
$$

Aggregating the capital demand $k_{t}(i)=A_{t}(i) x_{t}$ over $i$, and using the capital market clearance condition $\int_{0}^{M_{t}} k_{t}(i) d i=K_{t}$, one obtains:

$$
x_{t}=\frac{K_{t}}{M_{t} A_{t}}
$$

And by labor market clearance, we have

$$
\ell_{u}=(1-s) u \frac{L_{t}}{M_{t}}=(1-s) u
$$

Using these expressions in (2.23), and recognizing that $\int_{0}^{M_{t}} A_{t}(i) d i=M_{t} A_{t}$, aggregate output is:

$$
Y_{t}=\nu \cdot[(1-s) u]^{1-\alpha} \cdot K_{t}^{\alpha} \cdot\left(A_{t} L_{t}\right)^{1-\alpha}
$$

where $\nu=\frac{1}{\alpha(1-\alpha)}$ is a re-scaling constant which I drop for the remainder of the paper. The aggregate output of this economy displays constant returns to scale with labor-augmenting technological change.

Capital-output ratio in steady state is constant and it is a function of taste, technology and distortion parameters. As expected, it is decreasing in the level of distortions:

$$
\frac{K}{Y}=\frac{\alpha^{2}}{\left(r_{s s}+\delta\right)(1+\theta)} .
$$

In order to analyze the implications of the model on per-capita income, I transform variables into their stationary counterparts. I start with the TFP term. Revoking (2.13), the steady state limiting gap between the frontier and 
a country's productivity is a function of its skilled labor fraction. With a little abuse of notation in skipping the limit expression, this gap is given by:

$$
g(s)=\frac{A}{T}=\lambda^{-\frac{1}{\eta}} s^{\frac{\beta}{\eta}}
$$

Comparative statics with respect to $(s, \lambda)$ are intuitive. Relative technology is increasing in $s$ since a higher skilled labor supply facilitates technology adoption form the frontier. It is decreasing in the growth rate $\lambda$ since a rapidly expanding frontier makes catch-up harder.

Let $\tilde{y}$ denote normalized aggregate output per capita $Y_{t} /\left(L_{t} T_{t}\right)$. Substituting (2.25) into (2.23) and re-arranging terms, per-capita stationary income is equal to:

$$
\tilde{y}_{s s}=g(s) \cdot(1-s) \cdot u \cdot\left[\frac{\alpha^{2}}{\left(r_{s s}+\delta\right)(1+\theta)}\right]^{\frac{\alpha}{1-\alpha}} .
$$

The non-substitutability of the two types of labor causes per-capita income to display an inverse-U shaped relationship with $s$. Although $g(s)$ is increasing, it is bounded by one. As $s$ increases, there are not enough unskilled workers to undertake production tasks and this leads to a decline after a certain level of $s^{*}$ where $\tilde{y}_{s s}$ is maximized. Alternatively, as $u$ increases, the range of $s$ over which per-capita income is decreasing narrows. In other words, an economy with an increasing share of skilled labor in the workforce can escape a decline in per-capita income by increasing the efficiency of its unskilled labor.

In steady state, technology level $A_{t}$ grows at a stationary rate equal to $\lambda$, which is also the growth rate of per-capita quantities. Interest rate and rental rate of capital are constant:

$$
\begin{gathered}
r_{s s}=\rho+\lambda, \\
R_{s s}=\left(r_{s s}+\delta\right)(1+\theta) .
\end{gathered}
$$

The rental rate of capital is increasing in investment distortions which tend to make capital more costly.

Finally, I present the wage premium of the skilled over efficiency units of unskilled labor,

$$
\frac{\tilde{w}_{s}}{\tilde{w}_{u}}=\frac{\alpha \beta \lambda}{\eta \lambda+\rho} \frac{(1-s)}{s} u .
$$

As expected, the wage premium is decreasing in $s$ and increasing in $u$. A faster rate of growth in the frontier, reflected by a higher $\lambda$, leads to an increase in 
the wage premium, a similar result to Greenwood and Yorukoglu (1997). This result is quite intuitive. If the frontier expands at a faster rate, there is a greater stock of knowledge to adopt and the marginal product of skilled labor increases. A higher discount rate $\rho$, on the other hand, increases the interest rate which depresses the wage premium since hiring skilled labor is like an investment in technology.

The model generates predictions for the income level and the wage premium in equations (2.26) and (2.29) respectively. Next, I undertake a quantitative exercise to evaluate whether the model can simultaneously account for crosscountry and within-country income differences.

\section{Quantitative Implications of the Model}

In order to bring the model to data, I have to define and measure skilled labor in the most pertinent way. The technological frontier defines what type of formal or informal training makes a worker skilled. In the pre-industrial period, skilled craftsman were trained on-the-job through the apprenticeship system. The industrial revolution deskilled these workers and created a new set of knowledge necessary to be considered skilled. In the second half of the 20th century, college education became the channel of skill acquisition. In the following exercise, I measure skilled labor as scientists and engineers (S\&E) with a college degree.

The reason I restrict attention to be $\mathrm{S} \& \mathrm{E}$ degrees is that not all university majors are equally relevant for technology adoption activities. Murhpy et.al. (1991) report a positive relationship between the share of engineering majors in university enrollment and growth performance of countries. Enrollment in law, on the other hand, has a negative impact on growth. ${ }^{8}$

I choose 1985 as the year of analysis because the college enrollment in the US was relatively stationary around $25 \%$ between 1965-1980. ${ }^{9}$

\footnotetext{
${ }^{8}$ Murphy et.al. (1991) consider engineering and law majors as proxies for entrepreneurship versus rent-seeking. For the purpose of this paper, their empirical evidence shows that not all college degrees are the same from a growth perspective.

${ }^{9}$ Data from Current Population Survey, Historical Tables A-5a. Available in http://www.census.gov/population/www/socdemo/school.html
} 


\subsection{Calibration}

I calibrate the set of parameters $(\alpha, \delta, \lambda, \rho, \beta, \eta)$ by matching some key statistics of the US data to the steady state characteristics of the model and the evidence on the rate of convergence to the steady state.

The growth rate of per worker output in the model, $\lambda$, is set equal to 0.02 to match the average growth rate of real GDP per equivalent adult in the US between 1950-1985. Using this value, I set $\rho=0.02$ to match an average real interest rate of $r_{s s}=4 \%$ in (2.27).

The depreciation rate $\delta$ and the production function parameter $\alpha$ are calibrated to the US investment rate $N / Y$ and the capital-output ratio $K / Y$. The law of motion for capital implies that $\delta=N / K-\lambda$. The investment rate and capital-output ratio (based on yearly output) in the US are roughly 0.2 and 2.5 respectively. This implies $N / K=0.2 / 2.5=0.08$, and $\delta=0.06$. Finally, $\alpha$ is calibrated to match the capital-output ratio, given by expression (2.25), to its US value of 2.5 which yields $\alpha=0.5$.

The parameters of the technology adoption function, $(\beta, \eta)$, are pinned down by the implied rate of convergence to the steady state and the wage premium. In the Appendix, I show that the rate of convergence is equal to $\eta \lambda$. I set $\eta$ equal to 1 , the upper bound of permissible values for this parameter, to be consistent with the evidence of a rate convergence rate around 0.02 reported by Barro and Sala-i Martin (2004). Finally, I use the wage premium expression (2.29) and the US values for $(s, u, \theta)$ to pin down $\beta .^{10}$ Table 1 summarizes the parameter values.

\begin{tabular}{ccc} 
Parameter & Target & Value \\
\hline$\alpha$ & Capital-output ratio & 0.5 \\
$\delta$ & Investment rate/capital-output ratio & 0.06 \\
$\lambda$ & US per worker growth rate & 0.02 \\
$\rho$ & Real interest rate $(=\rho+\lambda)$ & 0.02 \\
$\eta$ & Speed of convergence to steady state $(=\eta \lambda)$ & 1 \\
$\beta$ & US wage premium & 0.30 \\
\hline \hline
\end{tabular}

Table 1 - Calibrated Parameters

\footnotetext{
${ }^{10}$ Scientist and engineers as a share of total US labor force is computed as $3.7 \%$ in 1985 . According to Heston et. al. (2006), the average relative price level of investment over that of consumption in US between 1950-1985 is one. In the one-sector model presented here, this ratio corresponds to $1+\theta_{u s}$ which yields $\theta_{u s}=0$. Details about the computation of $u$ and $s$ can be found in the Appendix.
} 
How does the assumption of no substitutability between the two types of human capital affect the calibration of $\beta$ ? It is more likely that skilled workers can substitute the unskilled but not the other way. In such a case, the equilibrium wages of both types will be equal if there are skilled workers in unskilled jobs. As long as all skilled workers are employed at technology adoption tasks, both types will be paid their marginal contribution and the wage premium expression above will hold. Also, given the measured $(u, s)$ levels, all countries fall into the range where where per-capita income is increasing is increasing in $s$.

The calibrated value of $\alpha$ equal to 0.5 is higher than the commonly used value of $1 / 3$. Note that although the model delivers the same aggregate production function (2.23) as the neoclassical model, its micro-foundations are quite different. Similarly high values for $\alpha$ are found to be consistent with the evidence on convergence rates in Howitt (2000). On the other hand, high $\alpha$ values amplify the effects of investment distortions given by $\theta$ differences. Restuccia and Urritia (2001) show that a value for the capital share around $5 / 6$ is needed so that the neoclassical model can explain income differences through observed investment distortions. This, however, implies a convergence rate too slow given the evidence. The model presented here is flexible enough to calibrate $\alpha$ to the capital-output ratio without being inconsistent with the evidence on the convergence rate.

\subsection{Cross-Country Income Differences}

In this section, I investigate whether the model can account for the cross-country income differences seen in the data. ${ }^{11}$ I assume that the parameter values for $(\alpha, \delta, \lambda, \rho, \beta, \eta)$ are common across economies. I use the steady state income expression (2.26) and the observed variation in $(s, u, \theta)$ to derive the crosscountry relative income predicted by the model for 1985. I choose the US as the benchmark country and compare the model-generated relative incomes,

$$
\frac{\tilde{y}_{i}}{\tilde{y}_{u s}}=\frac{1-s_{i}}{1-s_{u s}} \cdot\left(\frac{s_{i}}{s_{u s}}\right)^{\frac{\beta}{\eta}} \cdot \frac{u_{i}}{u_{u s}} \cdot\left(\frac{1+\theta_{u s}}{1+\theta_{i}}\right)^{\frac{\alpha}{1-\alpha}}
$$

with the observed ones. Data about relative price of investment and income are from Heston et.al (2006). The former is computed by taking the average

\footnotetext{
${ }^{11}$ Caselli (2005) provides a survey of the success of various models in that regard.
} 
price level of investment over that of consumption for the period 1950-1985. Observed income is real GDP per worker for the same year. I have a sample of 58 market economies countries with complete data.

I also calculate the results for two counterfactual experiments: In the first experiment, the stock of skilled labor is assumed to be the same across countries, so the income variations come from $u$ and $\theta$. In the second experiment, the level of distortions are assumed to be the same, and the income variation originates from differences in $u$ and $s$. These are reported as the "distortion-only model" and "no-distortion model" respectively. Figure 1 and Tables 2-4 summarize the results.

In general, the benchmark and the no-distortion models do a better job than the distortion-only model in matching key moments of data. They match the median accurately and underestimate the mean income level. Even at the relatively high value of the capital share, the distortion-only model overestimates both the mean and median income levels.

\begin{tabular}{lcccc} 
Statistic & Data & Benchmark Model & Distortion-only Model & No-distortion Model \\
\hline Mean & 0.43 & 0.36 & 0.52 & 0.36 \\
St. Dev. & 0.28 & 0.23 & 0.26 & 0.17 \\
Median & 0.35 & 0.33 & 0.47 & 0.34 \\
Min. & 0.04 & 0.09 & 0.11 & 0.14 \\
\hline \hline
\end{tabular}

Table 2 - Key Development Accounting Statistics

Table 2 documents the Pearson's correlation coefficient and rank correlations between the model-generated income levels with the data. Evidently, the nodistortion model does a better job than the distortion-only model in fitting the data in all three measures. The benchmark model further improves the fit because distortions are negatively correlated with skilled labor endowments.

\begin{tabular}{lccc} 
Statistic & Benchmark Model & Distortion-only Model & No-distortion Model \\
\hline Pearson's r & 0.60 & 0.46 & 0.54 \\
Spearman's rho & 0.62 & 0.51 & 0.58 \\
Kendall's tau & 0.44 & 0.35 & 0.43 \\
\hline \hline
\end{tabular}

Table 3 - Correlations of Predicted Incomes with the Data 
Table 4 reports income levels at various percentiles. The no-distortion model captures the variation up to the 80th percentile better than the distortion-only model. The distortion-only model generates income levels consistently higher than in the data for the $10 t h, 20 t h, 40 t h$ and $60 t h$ percentiles, but matches data quite well for the 80th and 90th percentiles.

\begin{tabular}{lcccc} 
Percentile & Data & Benchmark Model & Distortion-only Model & No-distortion Model \\
\hline 10th & 0.11 & 0.10 & 0.22 & 0.18 \\
20th & 0.16 & 0.16 & 0.28 & 0.22 \\
40th & 0.29 & 0.22 & 0.43 & 0.32 \\
60th & 0.43 & 0.40 & 0.54 & 0.37 \\
80th & 0.76 & 0.52 & 0.76 & 0.47 \\
90 th & 0.85 & 0.72 & 0.86 & 0.58 \\
\hline \hline
\end{tabular}

Table 4 - Relative Incomes at Various Percentiles

The benchmark model accurately predicts income levels of the poorest countries at the bottom of the distribution (10th and 20th percentiles), does a satisfactory job at intermediate ranges (40th and 60th percentiles) but its predictions are lower than the data at higher levels of income. In other words, according to the model, developed countries in general have too few scientists and engineers in the workforce to explain their relative income levels vis-à-vis the US.

This last point relates to the literature in the following way. Klenow and Rodríguez-Clare (2005) construct and calibrate a similar model with international diffusion and externalities. They measure technology adoption effort through R\&D investment. Quantitatively, they obtain the opposite results. Productivity (and thus income) levels of rich countries are accurately predicted but poor countries have too little R\&D investment to be consistent with their levels of development. They suggest that the 'true' research intensities are higher than the observed ones, and that informal research could be potentially important in non-OECD countries. ${ }^{12}$ The contribution of my paper is to capture this unobserved technology adoption effort through the measurement of the type of workers who are likely to be engaged in technology related activities regardless of whether they are employed in a formal $R \& D$ department or not.

\footnotetext{
${ }^{12}$ Córdoba and Ripoll (2007) obtain a similar result using an alternative model.
} 


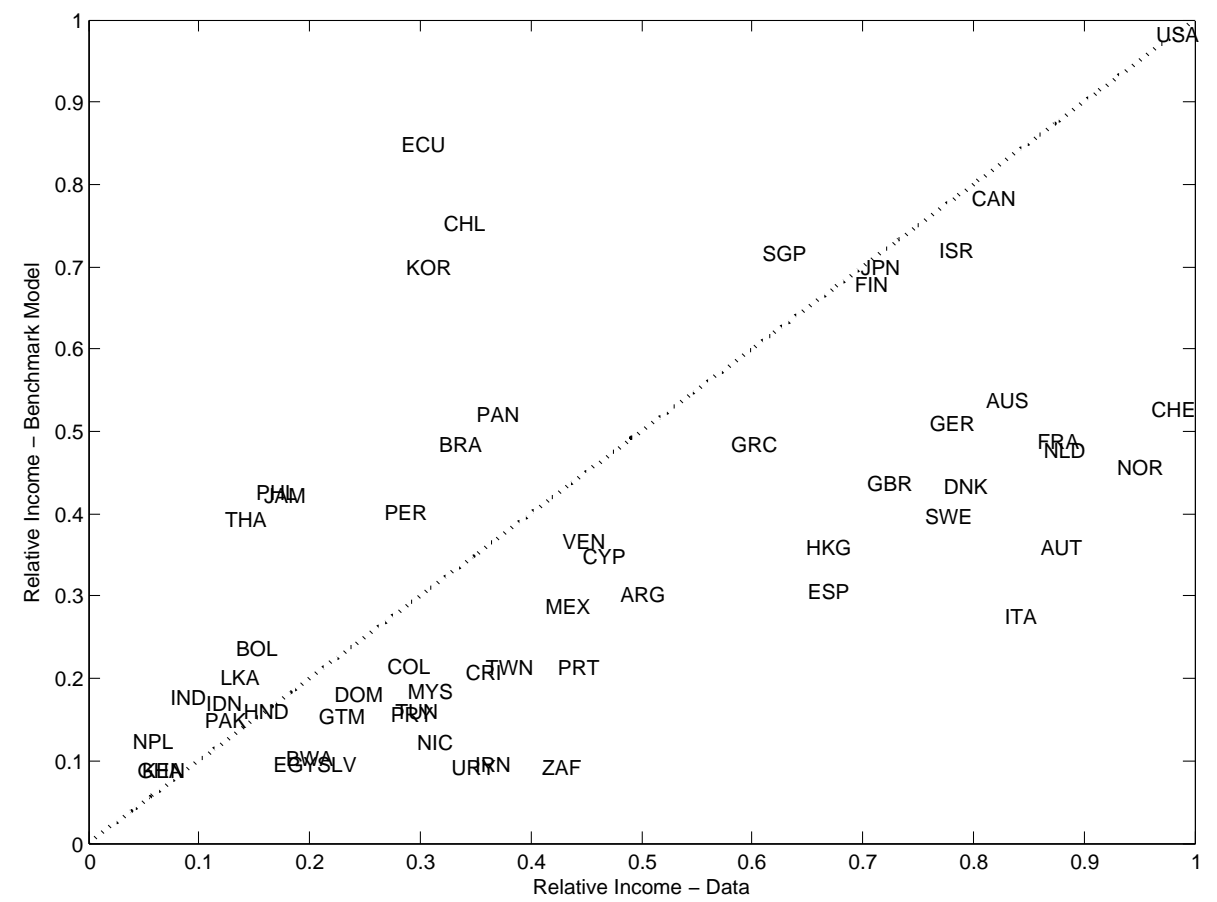

Figure 1: Relative Incomes, Benchmark Model vs. Data

Of course, human capital is not the only input into the technology adoption process. Real resources such as labs and equipment are used as well. The model, however, does not take them into account and is thus unable to explain higher income levels. A more elaborate model which includes both types of inputs is likely to explain the data better.

\subsection{Within-Country Income Differences}

I have disciplined the parameters of the model to be consistent with the US wage premium on skilled labor and used these values in the development accounting exercise above. In this section, I investigate whether the same parameter values, together with the observable variation in $(s, u)$, can explain within-country income differences as well.

Empirical wage premia are obtained using the cross-country rates of return education reported by Psacharopoulos (1994). The measurement of the wage premium is not based on a Mincerian approach because the rental rate of the two types of human capital are different. In the Mincer approach, human capital 
is measured in efficiency units and more educated workers are simply more efficient in performing the same task. In my model, the two types of human capital perform separate tasks and are paid different rental rates. I employ the method described in Psacharopoulos (1995) to back out the wage premia using the reported rates of return to education. Detailed description of the data is provided in the Appendix.

I report all wage premia in logs. The sub-sample for which data is available consists of 44 countries. The sample mean and standard deviation are 2.99 and 1.53 respectively. The US value used in calibration is 1.82 . Using expression (2.29), I generate wage premia predictions for the sub-sample of countries. Figure 2 plots these predictions against the data. ${ }^{13}$

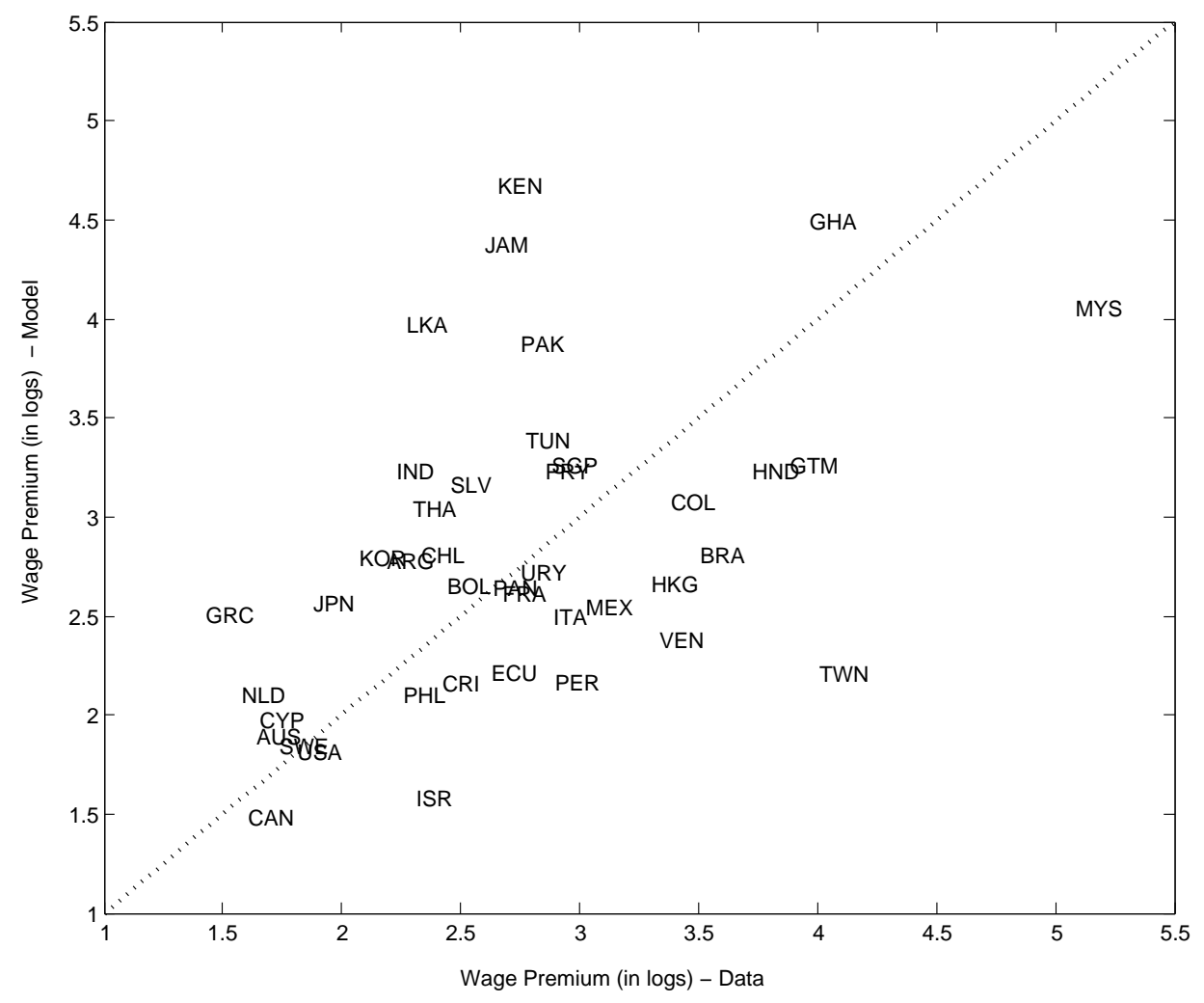

Figure 2: Wage Premia, Model vs. Data (in logs)

Both Pearson's product moment and Spearman's rank correlation coefficients between model predicted values (in logs) with the data are 0.43 in the

\footnotetext{
${ }^{13}$ Three outliers in the data - Portugal, Botswana and the Dominican Republic - are dropped from the sample presented in the figure.
} 
full sample and 0.48 when the three outliers are removed. Recovering the general slope of the distribution as it is evident in Figure 2 could be considered a success considering potential measurement problems in the data. The model does not systematically under- or overestimate the wage premia across countries. Given that the values are in logs, there is a non-negligible absolute error for some countries such as Jamaica, Kenya, Pakistan and Taiwan. Most of the countries, however, are aligned around the $45^{\circ}$ degree line. A total of 8 countries out of 41 (after excluding the outliers in the data) are predicted within $10 \%$ error margin, and 22 countries are within a $20 \%$ error margin.

In a recent contribution, Caselli and Coleman (2006) use country-specific wage premia to pin down unobserved productivity levels of skilled and unskilled labor and analyze whether these 'calibrated' productivity differences can explain income differences. The quantitative approach here differs from theirs in that it uses one observation (US wage premium) to discipline the relevant structural parameter, and resorts to observable variables only to generate predictions on cross- and within-country income differences.

\section{Conclusion}

What is the exact role of human capital in development? To answer that question, I propose a growth model in which firms employ skilled workers in order to augment their productivity by adopting technologies from a freely available stock of knowledge in the frontier. The variation in the skilled labor share leads to income differences between countries. The idea that human capital facilitates technology adoption goes back to Nelson and Phelps (1966). The first contribution I make is to build a general equilibrium model around it.

In the quantitative part, I calibrate model parameters to match some key statistics of the US data and measure skilled labor as scientist and engineers. The second contribution of the model is in that it successfully accounts for cross-country income differences, especially at the lower end of the sample. The main departure from the related quantitative literature is the idea that technology diffusion not only takes place through formal R\&D, but through the employment of skilled labor in general. Quantitatively, this channel seems to be relevant for countries up to the 60th percentile of the global income distribution. Previous research by Klenow and Rodríguez-Clare (2005) suggests that 
measured differences in formal R\&D expenditures across countries is able to explain top two income quantiles in a similar model with technology diffusion. A synthesis of the two models can potentially fit the whole distribution more satisfactorily.

The model also predicts within-country income differences between skilled and unskilled workers. When confronted with data, the model fits the wage premia of a subset of countries with some success. The third contribution of the model is that both cross- and within country income differences can be simultaneously accounted for using the same calibrated parameter values and variation in observable variables.

The implications of the results are twofold. First, the notion put forward by Nelson and Phelps (1966), that human capital contributes to the production process in a different way than direct inputs by being a facilitator of technology adoption seems to be quantitatively relevant. Second, some types of human capital which we denote as 'skilled' are more suitable to perform the technology adoption activities than others. Given the difference in tasks, it is a misspecification to aggregate all types of human capital into one single stock as it is done in most development accounting exercises. Models with disaggregated human capital, where the specific role played by each type is carefully considered (beyond simple capital-skills complementarity), could substantially improve our understanding of development. 


\section{$5 \quad$ References}

- Barro R.J, Lee J. International Data on Educational Attainment: updates and implications. Oxford Economic Papers 2001;3; 541-563.

- Barro R.J, Sala-i Martin X. Economic Growth. The MIT Press: Cambridge; 2004.

- Barro R.J, Sala-i Martin X. Technological Diffusion, Convergence, and Growth. Journal of Economic Growth 1997;2; 1-26.

- Benhabib, J, Spiegel M.M. The Role of Human Capital in Economic Development Evidence from Aggregate Cross-country Data. Journal of Monetary Economics 1994;34; 143-173.

- Benhabib J, Spiegel M.M. 2005. Human Capital and Technology Diffusion. In Aghion P, Durlauf S (Eds), Handbook of Economic Growth, North Holland: Amsterdam; 2005.

- Caselli F, 2005. Accounting for cross-country income differences. In Aghion P, Durlauf S (Eds), Handbook of Economic Growth, North Holland: Amsterdam; 2005.

- Caselli F, Coleman W.J.II. Cross-Country Technology Diffusion: The Case of Computers. American Economic Review 2001;91:2; 328-335.

- Caselli F., Coleman W.J.II. The World Technology Frontier. American Economic Review 2006;96:3; 499-522.

- Caselli F, Wilson D.J. Importing Technology. Journal of Monetary Economics 2004;51; 1-32.

- Córdoba J.C, Ripoll M. Endogenous TFP and Cross-Country Income Differences. Journal of Monetary Economics 2007;55; 1158-1170.

- Doms M, Dunne T, Troske K.R. Workers, Wages, and Technology. The Quarterly Journal of Economics 1997;112:1; 253-290.

- Eaton J, Kortum S. International Technology Diffusion: Theory and Measurement. International Economic Review 1999;40:3; 537-570.

-Erosa A, Koreshkova T, Restuccia D. How Important is Human Capital? A Quantitative Theory Assessment of World Income Inequality. University of Toronto, Department of Economics Working Paper 2007 March.

- Foster A.D, Rosenzweig M.R. Learning by Doing and Learning from Oth-

ers: Human Capital and Technical Change in Agriculture. The Journal of Political Economy 1995;103:6; 1176-1209. 
- Gordon R.J, Reflections on Pin Factory Visits. In Industrial Technology and Productivity: Incorporating Learning from Plant Visits and Interviews into Economic Research - NBER/Sloan Project Report, papers presented at the Annual Meetings of the American Economic Association, January, 2000. MA:Cambridge; 2000.

- Greenwood J, Yorukoglu M. 1974. Carnegie-Rochester Conference Series on Public Policy 1997;46; 49-95.

- Griffith R, Redding S, Van Reenen J. Mapping the two Faces of R\&D: Productivity Growth in a Panel of OECD Countries. The Review of Economics and Statistics 2004;86:4; 883-895.

- Grogger J, Eide E. Changes in College Skills and the Rise in the College Wage Premium. The Journal of Human Resources 1995;30:2; 280-310.

- Heston A, Summers R, Aten B. Penn World Table Version 6.2, Center for International Comparisons of Production, Income and Prices at the University of Pennsylvania, September 2006.

- Howitt P. Endogenous Growth and Cross-Country Income Differences. American Economic Review 2000;90:4; 829-846.

- Keller W. International Technology Diffusion. Journal of Economic Literature $2004 ; 42 ; 752-782$.

- Klenow P.J, Rodríguez-Clare A. Externalities and Growth. In Aghion P, Durlauf S (Eds), Handbook of Economic Growth, North Holland: Amsterdam; 2005.

- Manuelli R, Seshadri A. Human Capital and the Wealth of Nations. University of Wisconsin Department of Economics Working Paper. 2005 June.

- Murphy K.M, Shleifer A, Vishny R.W. The Allocation of Talent: Implications for Growth. The Quarterly Journal of Economics 1991;106:2; 503-530.

- Nelson R.R, Phelps E.S. Investment in Humans, Technological Diffusion, and Economic Growth. The American Economic Review 1966;56; 69-75.

- Papageorgiou C. Distinguishing Between the Effects of Primary and PostPrimary Education on Economic Growth. Review of Development Economics 2003;7:4; 622-635.

- Parente S.L, Prescott E.C. Barriers to Technology Adoption and Development. The Journal of Political Economy 1994;102:2; 298-321.

- Psacharopoulos G. Returns to Investment in Education: A Global Update. World Development 1994;22:9; 1325-1343. 
- Psacharopoulos G. The Profitability of Investment in Education: Concepts and Methods. The World Bank, Human Capital Development and Operations Policy, Working Papers 1995.

- Restuccia D, Urrutia C. Relative Prices and Investment Rates. Journal of Monetary Economics 2001;47; 93-121.

- Romer P. Endogenous Technological Change. Journal of Political Economicy 1990;98; 71-102.

- UNESCO, Higher Education: International Trends 1960-1970. The Unesco Press: Paris; 1975.

- Xu B. Multinational enterprises, technology diffusion, and host country productivity growth. Journal of Development Economics 2000;62; 477-493. 


\section{Appendix A Steady State Equilibrium}

In this section, I show the existence of an equilibrium along a balanced growth path (BGP) so that all variables grow at the same rate under certain parameter restrictions. There are two dynamic decisions in this economy: capital accumulation undertaken by households and skilled labor employment decision given by intermediate good producers. I solve these problems to characterize the equilibrium interest rate, rental price of capital and the wage premium along the proposed BGP. To find the equilibrium quantities and prices, I impose equilibrium conditions to the first order necessary conditions of these problems and check the sufficiency conditions. I derive the necessary restrictions on parameters to ensure the existence of the proposed BGP. The stability conditions are trivial since the technology adoption function approaches its steady state level monotonically, and capital accumulation dynamics are the same as in the neoclassical growth model.

\section{Household Problem}

The household problem is rather standard. Since households are identical, there will be no trade in shares and bonds in equilibrium. I suppress the bond market and consider the investment decisions for physical capital and shares. By a no-arbitrage condition, the interest rate $r_{t}$ on bonds will be equal to the rate of return on shares. Since household members equally split the total consumption, the relevant part of the objective function (2.18) is to maximize $C_{t}$. Household takes rental rate of capital $R_{t}$, dividends and share prices $\left(D_{t}, q_{t}\right)$, total wages $W_{t}$ and transfers $z_{t}$ as given and solves,

$$
\max _{\left\{C_{t}\right\},\left\{\mathrm{N}_{t}\right\},\left\{S_{t}\right\}} \int_{t=0}^{\infty} e^{-\left(\rho-g_{\ell}\right) t} \ln \left(C_{t}\right) d t,
$$

subject to $K_{0}$ and

$$
\begin{aligned}
C_{t}+(1+\theta) \mathrm{N}_{t}+q_{t} S_{t} & =W_{t}+R_{t} \mathrm{~K}_{t}+D_{t} a_{t}+z_{t} \\
\dot{K}_{t} & =\mathrm{N}_{t}-\delta \mathrm{K}_{t} \\
\dot{a}_{t} & =S_{t}
\end{aligned}
$$

Along a BGP, household level variables $\left\{C_{t}, \mathrm{~N}_{t}, W_{t}, \mathrm{~K}_{t}, D_{t}, z_{t}\right\}$ grow at the same rate $\lambda$ as the output. By the absence of trade in shares in equilibrium, share 
prices should also increase at the same rate. Suppressing the time subscripts, the Hamiltonian is

$$
J=e^{-\left(\rho-g_{\ell}\right) t} \ln (C)+\mu_{\mathrm{K}} \cdot(\mathrm{N}-\delta \mathrm{K})+\mu_{a} \cdot S
$$

Necessary and sufficient conditions for the optimum read as

$$
\begin{gathered}
\frac{\partial J}{\partial \mathrm{N}}=0 \quad \Rightarrow \quad \mu_{\mathrm{K}}=e^{-\left(\rho-g_{\ell}\right) t} \frac{1+\theta}{C}, \\
\frac{\partial J}{\partial S}=0 \quad \Rightarrow \quad \mu_{a}=e^{-\left(\rho-g_{\ell}\right) t} \frac{q}{C} \\
\frac{\partial J}{\partial \mathrm{K}}+\dot{\mu}_{\mathrm{K}}=0 \quad \Rightarrow \quad \dot{\mu}_{\mathrm{K}}=-e^{-\left(\rho-g_{\ell}\right) t} \frac{R}{C}+\delta \mu_{\mathrm{K}}, \\
\frac{\partial J}{\partial a}+\dot{\mu}_{a}=0 \quad \Rightarrow \quad \dot{\mu}_{a}=-e^{-\left(\rho-g_{\ell}\right) t} \frac{D}{C}, \\
\lim _{t \rightarrow \infty}\left[\mu_{\mathrm{K}}(t) \mathrm{K}(t)\right]=0 . \\
\lim _{t \rightarrow \infty}\left[\mu_{a}(t) a(t)\right]=0 .
\end{gathered}
$$

First divide (A.4) by (A.2) to get:

$$
\frac{\dot{\mu}_{a}}{\mu_{a}}=-\frac{D}{q} .
$$

Then I take the logarithm of (A.2) and differentiate the resulting expression with respect to $t$. In a BGP, total consumption $C_{t}$ grows at a rate equal to $\lambda+g_{\ell}$. Using $\frac{\dot{C}}{C}=\lambda+g_{\ell}$,

$$
\frac{\dot{\mu}_{a}}{\mu_{a}}=-(\rho+\lambda)+\frac{\dot{q}}{q},
$$

which implies

$$
\frac{D+\dot{q}}{q}=\rho+\lambda
$$

This is the net rate of return to shares which is the sum of dividend and capital gains. 
The rental rate of capital is obtained by differentiating (A.1) with respect to $t$ to obtain

$$
\frac{\dot{\mu}_{\mathrm{K}}}{\mu_{\mathrm{K}}}=-(\rho+\lambda)
$$

and dividing (A.3) by this expression,

$$
R_{s s}=(\rho+\lambda+\delta)(1+\theta)
$$

The net interest rate in the bond market is equal to the rate of return to shares by a no-arbitrage condition:

$$
r_{s s}=\rho+\lambda
$$

Since $\mu_{\mathrm{K}}$ is decreasing at a rate $\rho+\lambda$, and household capital stock $K_{t}$ is growing by $\lambda+g_{\ell}$, the assumption $\rho>g_{\ell}$ makes sure that the transversality condition (A.5) is satisfied. Since $\mu_{a}$ is decreasing by a rate $\rho$, and $a_{t}$ is constant, the second transversality condition (A.6) is also satisfied.

\section{Intermediate Good Producer's Problem}

Henceforth I will refer the representative intermediate good producer as 'the firm'. The firm enjoys monopoly rents. Hence its net profit after rental payments is positive. Skilled labor is paid out of this rent. Now I solve firm's dynamic problem of skilled labor demand. I will derive the parameter restriction needed to ensure that the firm has enough rents to cover the decentralized wage rate along the proposed BGP.

Given $w_{s, t}$, when the firm employs a measure of $\ell_{s, t}$ skilled, its profit and resulting change in its technology are given by

$$
\begin{gathered}
\Pi_{t}=A_{t} x_{t}^{\alpha} \ell_{u}^{1-\alpha}-w_{s, t} \ell_{s, t}, \\
\dot{A}_{t}=\ell_{s, t}^{\beta}\left(\frac{T_{t}}{A_{t}}\right)^{\eta} A_{t}, \quad \beta \in(0,1), \quad \eta \in(0,1) .
\end{gathered}
$$

I restrict attention to the constant interest rate $r_{s s}$ along the BGP. The firm with an initial technology level $A_{0}$ solves the following problem:

$$
V\left(A_{0}\right)=\max _{\left\{\ell_{s, t}\right\}} \int_{t=0}^{\infty} e^{-r_{s s} \cdot t} \Pi_{t} d t,
$$


subject to (A.7) and (A.8).

Note that $x_{t}=x=k_{t} / A_{t}$ is constant along the BGP. Since wages grow by $\lambda$, I normalize wages and productivity by $T_{t}$. Let $\tilde{w}$ denote the stationary wage level. As in the text, $g=A_{t} / T_{t}$ is the gap between a country's productivity and the frontier. The problem in (A.9) can be rewritten as

$$
\begin{aligned}
V\left(A_{0}\right) & =\max _{\left\{\ell_{s, t}\right\}} \int_{t=0}^{\infty} e^{-r_{s s} \cdot t} T_{t} \frac{\Pi_{t}}{T_{t}} d t \\
& =\max _{\left\{\ell_{s, t}\right\}} \int_{t=0}^{\infty} e^{-\rho \cdot t} \cdot\left[g_{t} x^{\alpha} \ell_{u}^{1-\alpha}-\tilde{w}_{s} \ell_{s}\right] d t,
\end{aligned}
$$

subject to

$$
\dot{g}_{t}=\ell_{s}^{\beta} g_{t}^{1-\eta}-\lambda g_{t} .
$$

We present the Hamiltonian and the first order necessary conditions. Imposing equilibrium properties, we derive the wage premium. Lastly, we check that the sufficiency condition and transversality condition are satisfied. Suppressing the time subscripts,

$$
\begin{array}{r}
H\left(g, \ell_{s},\right)=e^{-\rho \cdot t} \cdot\left[g x^{\alpha} \ell_{u}^{1-\alpha}-\tilde{w}_{s} \ell_{s}\right]+\mu \cdot\left[\ell_{s}^{\beta} g^{1-\eta}-\lambda g\right], \\
\frac{\partial H}{\partial \ell_{s}}=0 \quad \Rightarrow \quad e^{-\rho \cdot t} \tilde{w}_{s}=\mu \beta \ell_{s}^{\beta-1} g^{1-\eta} \\
\frac{\partial H}{\partial g}+\dot{\mu}=0 \Rightarrow \quad \dot{\mu}=-e^{-\rho \cdot t} x^{\alpha} \ell_{u}^{1-\alpha}+\mu\left[\ell_{s}^{\beta}(\eta-1) g^{-\eta}+\lambda\right] .
\end{array}
$$

Rearrange (A.10) to get

$$
\mu=\frac{e^{-\rho \cdot t} \tilde{w}_{s}}{\beta \ell_{s}^{\beta-1} g^{1-\eta}},
$$

and divide (A.11) by (A.12),

$$
\frac{\dot{\mu}}{\mu}=-\frac{x^{\alpha} \ell_{u}^{1-\alpha}}{\tilde{w}_{s}} \beta \ell_{s}^{\beta-1} g^{1-\eta}+\ell_{s}^{\beta}(\eta-1) g^{-\eta}+\lambda .
$$

Taking the logarithm of (A.12) and differentiating with respect to $t$, and 
using the steady state condition $\dot{g}=0$, I get

$$
\frac{\dot{\mu}}{\mu}=-\rho
$$

Letting (A.13) and (A.14) equal, I obtain an expression for skilled wages: Imposing the equilibrium condition $\ell_{s}=s$, these two equations read as;

$$
\tilde{w}_{s}=x^{\alpha} \ell_{u}^{1-\alpha} \frac{\beta \ell_{s}^{\beta-1} g^{1-\eta}}{\ell_{s}^{\beta}(\eta-1) g^{-\eta}+\lambda+\rho} .
$$

Total payments to skilled labor are given by

$$
\tilde{w}_{s} \cdot \ell_{s}=g x^{\alpha} \ell_{u}^{1-\alpha} \frac{\beta \ell_{s}^{\beta} g^{-\eta}}{\ell_{s}^{\beta}(\eta-1) g^{-\eta}+\lambda+\rho} .
$$

Under some additional conditions, the sufficiency of necessary conditions is guaranteed by Arrow-Kurz sufficiency theorem for dynamic control. The maximized Hamiltonian $H^{\circ}(g)$ is obtained when one solves (A.10) for optimal $\ell_{s}(g)$ and inserts this back into $H\left(\ell_{s}, g\right)$. Arrow-Kurz's sufficiency condition is the concavity of $H^{o}$ in $g .{ }^{14}$ The maximized Hamiltonian of this problem is

$$
H^{o}(g)=g^{\frac{1-\eta}{1-\beta}}\left(\beta^{\frac{\beta}{1-\beta}}-\beta^{\frac{1}{1-\beta}}\right) .
$$

One can check that $\frac{\partial^{2} H^{o}}{\partial g^{2}} \leq 0$ is satisfied if either of the following restrictions hold:

$$
\begin{aligned}
& \text { i. } \quad \beta \in(0,1) \text { and } \eta \in[\beta, 1] \text {, or } \\
& \text { ii. } \quad \beta>1, \quad \eta>0 \text { and } \eta \notin(1, \beta) \text {. }
\end{aligned}
$$

In the text, I assume that the former condition holds. The restriction on $\beta$ ensures that demand for skilled human capital is finite. As to $\eta$, if this parameter is larger than 1, it is optimal for the firm to delay investment in technology adoption, to let $T_{t} / A_{t}$ increase over time such that the returns to hiring skilled labor is infinite in an indefinite future period.

The firm has enough rents to pay skilled labor if

$$
g x^{\alpha} \ell_{u}^{1-\alpha}-\tilde{w}_{s} \ell_{s} \geq 0
$$

\footnotetext{
${ }^{14}$ The reader can refer to Barro and Sala-i Martin (2004), page 610.
} 
Substituting the steady state gap $g=\lambda^{-\eta} \ell_{s}^{\beta / \eta}$ in (A.15), one can check that this condition is satisfied for

$$
\rho>(\beta-\eta) \lambda
$$

This parameter restriction is needed to assure that the firm has enough resources to support technology investment in form of skilled labor hiring in a decentralized economy. Note that (A.16) holds under the assumption $\eta \geq \beta$ already assumed above.

Lastly, the transversality condition is given by

$$
\lim _{t \rightarrow \infty} \mu_{t} \cdot g_{t}=0
$$

and it is satisfied since $g$ is constant in steady state and $\mu$, as one can see in (A.10), is declining at the rate $\rho$.

\section{Capital-Output Ratio}

To find the steady state capital-output ratio, start rearranging term in (2.5), the demand function for capital by intermediate good producers:

$$
\left(\frac{x}{\ell_{u}}\right)^{1-\alpha}=\frac{\alpha}{1-\alpha} \frac{1}{R_{s s}} .
$$

The contribution of each producer to nation output is given by: $y=A \frac{x^{\alpha} \ell_{u}^{1-\alpha}}{\alpha(1-\alpha)}$. Using the production function for $x=\frac{k}{A}$, I obtain:

$$
\frac{k}{y}=\alpha(1-\alpha)\left(\frac{x}{\ell_{u}}\right)^{1-\alpha} .
$$

Inserting $\left(x / \ell_{u}\right)^{1-\alpha}$ from above, the capital-output ratio for the representative intermediate good producer reads as;

$$
\frac{k}{y}=\frac{\alpha^{2}}{\left(r_{s s}+\delta\right)(1+\theta)} .
$$

The aggregate capital-output ratio is the same since $K=k M$, and $Y=y M$.

\section{Wage Premium}

The final good producer pays unskilled labor according to its marginal con- 
tribution in production. Total payments to unskilled labor (in efficiency units) amount to

$$
w_{u, t} L_{u, t}=\frac{A_{t}}{\alpha}\left(x_{t} M_{t}\right)^{\alpha} L_{u, t}^{1-\alpha} .
$$

In order to derive the wage premium, I divide both sides of this expression by $M_{t}$, normalize by $T_{t}$ and find the payment to unskilled labor per variety:

$$
\tilde{w}_{u} \ell_{u}=\frac{g}{\alpha} x^{\alpha} \ell_{u}^{1-\alpha}
$$

Dividing (A.15) by (A.19),

$$
\frac{\tilde{w}_{s}}{\tilde{w}_{u}}=\frac{\alpha \beta \ell_{s}^{\beta-1} g^{-\eta}}{\ell_{s}^{\beta}(\eta-1) g^{-\eta}+\lambda+\rho} \ell_{u} .
$$

Substituting the steady state $g$, I get

$$
\frac{\tilde{w}_{s}}{\tilde{w}_{u}}=\frac{\alpha \beta \lambda}{\eta \lambda+\rho} \frac{\ell_{u}}{\ell_{s}} .
$$

In equilibrium, $\ell_{u}=(1-s) u$ and $\ell_{s}=s$ which yields (2.29) in the text.

\section{Rate of Convergence}

In steady state, a constant fraction $\sigma \in(0,1)$ of household income will be saved. We can write the law of motion for per-capita capital normalized with respect to $T_{t}$ as

$$
\frac{\dot{k}}{k}=f^{1}(k, g)=v g^{1-\alpha} k^{\alpha-1}-\left(g_{\ell}+\delta+\lambda\right)
$$

where $v=\sigma /(\alpha(1-\alpha))$. The steady state value of $k$ is given by

$$
k^{*}=\left[\frac{v}{g_{\ell}+\delta+\lambda}\right]^{\frac{1}{1-\alpha}} g^{*} .
$$

The law of motion for the technological gap is

$$
\frac{\dot{g}}{g}=f^{2}(g)=\ell_{s}^{\beta} g^{-\eta}-\lambda,
$$

and its steady state value is

$$
g^{*}=\ell_{s}^{\frac{\beta}{\eta}} \lambda^{-\frac{1}{\eta}}
$$


Log-linearizing $f^{1}(k, g)$ and $f^{2}(g)$ around the steady state yields

$$
\begin{aligned}
\tilde{f}^{1}(k, g) & =(1-\alpha)\left(g_{\ell}+\delta+\lambda\right)\left[\frac{g}{g^{*}}-\frac{k}{k^{*}}\right], \\
\tilde{f}^{2}(g) & =\eta \lambda\left[1-\frac{g}{g^{*}}\right] .
\end{aligned}
$$

The system of differential equations around the steady state can be written as

$$
\left[\begin{array}{c}
\dot{k} / k \\
\dot{g} / g
\end{array}\right]=\left[\begin{array}{cc}
-(1-\alpha)\left(g_{\ell}+\delta+\lambda\right) & (1-\alpha)\left(g_{\ell}+\delta+\lambda\right) \\
0 & -\eta \lambda
\end{array}\right] \cdot\left[\begin{array}{l}
k-k^{*} \\
g-g^{*}
\end{array}\right]
$$

which has two roots $\epsilon_{1}=(1-\alpha)\left(g_{\ell}+\delta+\lambda\right)$ and $\epsilon_{2}=\eta \lambda$. Plugging in the calibrated parameter values for $(\alpha, \lambda, \delta)$ and using the population growth rate $g_{\ell}=1.5 \%$, the first root is $\epsilon_{1}=0.0475$. Since this is much larger than the empirical estimates of the rate of convergence, I assume that $\epsilon_{2}$ is the smaller root and hence the rate of convergence. 


\section{Appendix B Data}

\section{Human Capital Stocks}

I measure $s$ by the share of scientists and engineers in workforce at year 1985. This is computed using two pieces of evidence. Barro-Lee (2001) data provides the college attainment levels of countries. UNESCO (1975) reports the share of majors in total enrollment.

The efficiency level of unskilled human capital is measured using the countryspecific Mincerian returns in Psacharopoulos (1994) and average years of schooling in Barro-Lee (2001). Following the standard procedure in the literature, in a country in which the Mincerian return is $r$ and average years of schooling is $m$, total stock of unskilled labor is equivalent to $\exp (r \cdot m)$ units of efficiency labor.

\section{Measurement of the Wage Premium}

I measure the wage premium in two steps. First, I obtain the relative earnings ratio of an average college graduate over a worker with no education (college premium). Next, I use the premium of an engineering major over the average college graduate. Grogger and Eide (1995) provide estimates of major-specific wage premia in the US. Their estimate of engineering premium is 1.2 (over earnings of an average college graduate). Psacharopoulos (1994) reports a similar measure for a limited group of countries. These estimates do not systematically vary with income levels. Thus, I use the US value for other countries in the sample as well.

The measurement of the college premium follows the private rate of return method proposed by Psacharopoulos (1995) and is based on returns to investment in education data in Psacharopoulos (1994) (Table A1). The Mincerian method, used to construct of the human capital stocks $u$, is based on the assumption that there is a rental price for efficiency units of labor and workers of different skill levels are substitutable in production. Education enables a worker to produce more of the same. This assumption is valid when $u$ is imputed because efficiency units of human capital embedded in unskilled workers with different education levels are substitutable in the model. However, skilled and unskilled labor are not substitutable and paid different the rental rates. The private rate of return method is appropriate to back out the underlying 
wage premium based on the estimated rates of return.it

Let $P$ stand for life-expectancy in a country. Also, let $D$ indicate the duration of finishing a particular level of education. After finishing the school, the worker earns $w_{s}$ for the rest of her life whereas the uneducated worker earns $w_{u}$. Given a private rate of return $r$, the discounted life-time gain of obtaining a degree is equal to the opportunity cost plus the direct $\operatorname{cost} c$ :

$$
\sum_{t=1}^{P-D} \frac{w_{s}-w_{u}}{(1+r)^{t}}=\sum_{t=1}^{D}\left(w_{u}+c\right)(1+r)^{t} .
$$

From this equation, one can calculate $w_{s} / w_{u}$. We have country specific data on $r$ for primary, secondary and tertiary education as well as life-expectancy $P .{ }^{15}$ The direct $\operatorname{cost} c$ is taken as zero for all levels of education in all countries except college education in the US. The case for the calibration target, the US value, is discussed below. I calculate the wage ratio for each education level (college over secondary, secondary over primary and primary over no education.) The college premium is obtained by multiplying these three ratios.

Psacharopoulos (1994) reports only the social rate of return for the US. Most of the higher education expenses in the US are, however, privately financed. In the absence of externalities, the social return will be close to the private return. Thus, I use the $10 \%$ rate of return for secondary and $12 \%$ rate of return for higher education in the US. I also compute an estimate of the relative direct cost of higher education in terms of the unskilled wage level, $c / w_{u}$, in the US for 1975. According to the US Department Education, the total cost of a year of college education was $\$ 2,275$ in 1975 in current dollars. ${ }^{16}$ In the same year, minimum wage was $\$ 2.1$. An unskilled laborer working for 8 hours a day, 5 days a week for 9 months of school time would earn $\$ 3.275$ on total. This yields an estimate of $c / w_{u}=0.7$. Using this figure, and a life expectancy of $P=71$ years, the US college wage premium is estimated as 5.1. Using the engineering premium of 1.2 , the calibration target is $w_{s} / w_{u}=6.13$.

\footnotetext{
${ }^{15}$ International Life expectancy data is from US Census Bureau (http://www.census.gov/ipc/www/idb/idbprint.html). I take the 1975 value whenever possible to capture the educational choice of the average workforce in 1985. For many countries, data in this year is available. Otherwise, I choose the date closest to 1975 . The results are not sensitive to small changes in life expectancy.

${ }^{16}$ Data on college costs available in http://nces.ed.gov/programs/digest/d06/tables/dt06_319.asp
} 


\begin{tabular}{|c|c|c|c|c|c|c|}
\hline Country & Code & $y_{i} / y_{u s}$ & $u_{i}$ & $s_{i}$ & $1+\theta_{i}$ & $\log \left[\left(w_{s} / w_{u}\right)_{i}\right]$ \\
\hline Argentina & ARG & 0.48 & 2.00 & 0.009 & 1.40 & 2.19 \\
\hline Australia & AUS & 0.81 & 2.24 & 0.024 & 1.15 & 1.64 \\
\hline Austria & AUT & 0.86 & 1.81 & 0.006 & 0.95 & - \\
\hline Bolivia & BOL & 0.13 & 1.57 & 0.008 & 1.35 & 2.44 \\
\hline Botswana & BWA & 0.18 & 1.76 & 0.001 & 1.89 & 9.79 \\
\hline Brazil & BRA & 0.32 & 1.61 & 0.007 & 0.65 & 3.51 \\
\hline Canada & CAN & 0.80 & 2.52 & 0.040 & 1.02 & 1.61 \\
\hline Chile & CHL & 0.32 & 2.06 & 0.009 & 0.58 & 2.33 \\
\hline Colombia & $\mathrm{COL}$ & 0.27 & 1.79 & 0.006 & 1.56 & 3.39 \\
\hline Costa Rica & CRI & 0.34 & 1.56 & 0.013 & 1.75 & 2.42 \\
\hline Cyprus & CYP & 0.45 & 1.51 & 0.015 & 1.06 & 1.65 \\
\hline Denmark & DNK & 0.77 & 1.53 & 0.020 & 0.93 & - \\
\hline Dominican Republic & DOM & 0.22 & 1.43 & 0.020 & 2.08 & 5.58 \\
\hline Ecuador & $\mathrm{ECU}$ & 0.28 & 1.92 & 0.015 & 0.55 & 2.63 \\
\hline Egypt & EGY & 0.17 & 1.16 & 0.005 & 2.18 & - \\
\hline El Salvador & SLV & 0.21 & 1.30 & 0.004 & 2.25 & 2.46 \\
\hline Finland & FIN & 0.69 & 1.92 & 0.015 & 0.69 & - \\
\hline France & FRA & 0.86 & 2.08 & 0.011 & 0.95 & 2.69 \\
\hline Germany & GER & 0.76 & 2.00 & 0.008 & 0.80 & - \\
\hline Ghana & GHA & 0.04 & 1.23 & 0.001 & 1.55 & 3.97 \\
\hline Greece & GRC & 0.58 & 1.70 & 0.010 & 0.76 & 1.43 \\
\hline Guatemala & GTM & 0.21 & 1.44 & 0.004 & 1.56 & 3.88 \\
\hline Honduras & HND & 0.14 & 1.39 & 0.004 & 1.46 & 3.72 \\
\hline Hong Kong & HKG & 0.65 & 1.58 & 0.008 & 0.90 & 3.3 \\
\hline India & IND & 0.07 & 1.39 & 0.004 & 1.32 & 2.23 \\
\hline Indonesia & IDN & 0.11 & 1.29 & 0.001 & 0.85 & - \\
\hline Iran & IRN & 0.35 & 1.36 & 0.001 & 0.65 & - \\
\hline Israel & ISR & 0.77 & 1.78 & 0.026 & 0.70 & 2.31 \\
\hline Italy & ITA & 0.83 & 1.17 & 0.007 & 0.83 & 2.89 \\
\hline Jamaica & JAM & 0.16 & 3.29 & 0.003 & 1.2 & 2.60 \\
\hline Japan & JPN & 0.70 & 3.08 & 0.017 & 1.11 & 1.88 \\
\hline Kenya & KEN & 0.05 & 1.46 & 0.001 & 1.86 & 2.66 \\
\hline Korea (South) & KOR & 0.29 & 2.96 & 0.013 & 0.99 & 2.07 \\
\hline Malaysia & MYS & 0.29 & 1.58 & 0.002 & 1.17 & 5.08 \\
\hline Mexico & MEX & 0.41 & 1.41 & 0.008 & 1 & 3.03 \\
\hline Nepal & NPL & 0.04 & 1.08 & 0.002 & 1.19 & - \\
\hline Netherlands & NLD & 0.86 & 1.70 & 0.015 & 0.87 & 1.57 \\
\hline Nicaragua & NIC & 0.30 & 1.47 & 0.008 & 2.47 & - \\
\hline Norway & NOR & 0.93 & 1.59 & 0.014 & 0.83 & - \\
\hline Pakistan & PAK & 0.11 & 1.32 & 0.002 & 1.22 & 2.75 \\
\hline Panama & PAN & 0.35 & 2.34 & 0.012 & 1.03 & 2.63 \\
\hline Paraguay & PRY & 0.27 & 1.74 & 0.005 & & 2.85 \\
\hline Peru & PER & 0.27 & 1.57 & 0.013 & 0.92 & 2.89 \\
\hline Philippines & PHL & 0.15 & 2.28 & 0.020 & 1.41 & 2.25 \\
\hline Portugal & PRT & 0.42 & 1.36 & 0.005 & 1.14 & 7.36 \\
\hline Singapore & SGP & 0.61 & 1.80 & 0.005 & 0.45 & 2.88 \\
\hline South Africa & ZAF & 0.41 & 1.24 & 0.003 & 2.08 & - \\
\hline Spain & ESP & 0.65 & 1.47 & 0.008 & 0.98 & - \\
\hline Sri Lanka & LKA & 0.12 & 1.45 & 0.002 & 0.98 & 2.27 \\
\hline Sweden & SWE & 0.76 & 1.59 & 0.018 & 1.02 & 1.74 \\
\hline Switzerland & $\mathrm{CHE}$ & 0.99 & 2.10 & 0.013 & 0.95 & - \\
\hline Taiwan & TWN & 0.36 & 1.51 & 0.012 & 1.62 & 4.01 \\
\hline Thailand & THA & 0.12 & 1.73 & 0.006 & 0.83 & 2.3 \\
\hline Tunisia & TUN & 0.28 & 1.22 & 0.003 & 1.17 & 2.77 \\
\hline United Kingdom & GBR & 0.70 & 1.78 & 0.014 & 0.97 & - \\
\hline United States & USA & 1.00 & 3.23 & 0.037 & 1 & 1.82 \\
\hline Uruguay & URY & 0.33 & 1.88 & 0.009 & 4.34 & 2.75 \\
\hline Venezuela & VEN & 0.43 & 1.65 & 0.011 & 1 & 3.34 \\
\hline
\end{tabular}

